\title{
A REVIEW STUDY ON ENERGY HARVESTING SYSTEMS FOR VEHICLES
}

\author{
Umut AKSU, Recep HALICIOGLU
}

\begin{abstract}
The widespread and increasing consumption of fossil-based fuels as an energy source causes a rapid decrease of these natural sources, as well as an increase of pollution in the atmosphere. Fuel oil, one of the products of fossil fuels, is today the commonly used energy source for transportation. The importance of contributing to the fuel economy and of increasing environmental consciousness have necessitated certain measures in the automotive sector, as well as in other industrial sectors. Therefore, the technological developments recently carried out in the automotive sector aim to reduce the consumption of fossil fuels, for example by recovering waste energy in vehicles. In this direction, efforts have been centered upon the development of energy harvesting systems that provide energy recovery from dynamic parts of the vehicles, such as suspensions. Moreover, the regenerative braking systems that recover some amount of kinetic energy of the vehicles slowing down have been developed and have been in use long since. In this study, research studies on providing the recovery of the vehicles' waste energy are reviewed with their comparisons.
\end{abstract}

Keywords: energy harvesting; hybrid/electrical vehicles; regenerative braking; vehicle suspension systems; vehicle vibrations

\section{INTRODUCTION}

Energy requirements which have increased continuously from day to day have to a considerable extent been met with fossil fuels. However, besides the environmental problems arising from the use of fossil fuels, a steady decline of fossil fuel sources directed researchers to new researching subjects such as energy-saving systems, energy recovery mechanisms and the discovery of clean energy resources. In the global framework, the highest share with the percentage of 64.5 consumption of oil and by-products belongs to the transportation sector [1]. Moreover, the transportation sector has a significant share $(14 \%)$ in the total amount of greenhouse gas emissions to the atmosphere [2]. Given these considerations, there have been considerable interests in the study of increasing energy efficiency for road vehicles such as automobiles, that have the most common usage in transport.

In this study, previous studies about the energy harvesting systems developed for vehicles are compiled and discussed in terms of their comparative and similar features.

\section{ENERGY HARVESTING TECHNOLOGIES FOR VEHICLES}

In vehicles, fuel efficiency is below $75 \%$ due to various losses. A significant amount of total energy loss in the vehicle is caused by irreversibilities (thermal losses, friction losses, pump losses, incomplete combustion, etc.) that occur in the engine section. Reducing the energy losses through the engine and increasing engine efficiency are also other research interests [3-5]. For example, for an ordinary car in urban transportation, the power transferred to various parts of the vehicle and the known energy losses are given in Tab. $1[6]$.

The amount of energy required for the movement and management of a car constitutes $22.5 \%$ of the total energy consumed. This amount is the sum of the energy used to move the wheels against various road and weather resistances, along with the power used at the powertrain and other losses [6]. Considering the importance of fuel economy and energy efficiency, studies have been conducted to reduce energy losses, even for very small quantities, to the minimum at the powertrain of the vehicle. Within the scope of these studies, regenerative braking systems and energy harvesting suspension systems are the subjects of the research.

Table 1 Energy consumption distributions of an ordinary automobile in the urban transport [6]

\begin{tabular}{|l|c|}
\hline Engine losses & $\mathbf{7 5 . 2} \%$ \\
\hline - Thermal losses & $63.5 \%$ \\
\hline - Pumping losses & $5 \%$ \\
\hline - Combustion inefficiency & $3.4 \%$ \\
\hline - Friction losses & $3.3 \%$ \\
\hline Auxiliary & $\mathbf{2 . 3} \%$ \\
\hline - Alternator & $2.3 \%$ \\
\hline Power to wheels & $\mathbf{2 2 . 5 \%}$ \\
\hline - Vehicle inertia & $5.7 \%$ \\
\hline - Aerodynamic drag & $3.8 \%$ \\
\hline - Rolling resistance & $3.8 \%$ \\
\hline - Torque converter & $1.7 \%$ \\
\hline - Other drag & $1.7 \%$ \\
\hline - Transmission & $1.4 \%$ \\
\hline - Differential & $1.2 \%$ \\
\hline - Others & $3.2 \%$ \\
\hline
\end{tabular}

By definition, energy recovery is the conversion of energy losses occurring in various stages of the processes occurring in mechanical systems that are powered by an energy source into the form of available energy through specially designed devices and re-use in the case of need. The recovered/harvested energy can be used to actuate various electrical devices such as wireless sensors converted to electrical energy in very small quantities [7].

\subsection{Vehicle Suspensions and Energy Harvesting}

Vibration in vehicles is an undesirable phenomenon. Besides the increase of fuel consumption, the failure of vehicle components, vibrations at the other structures and environment, deterioration of passengers' comfort and driving safety are among the known harmful effects of 
vehicle vibrations [8]. Vehicle vibrations can occur when wheels pass over a structural fault or obstacle on the road and the vehicle accelerates or decelerates [9].

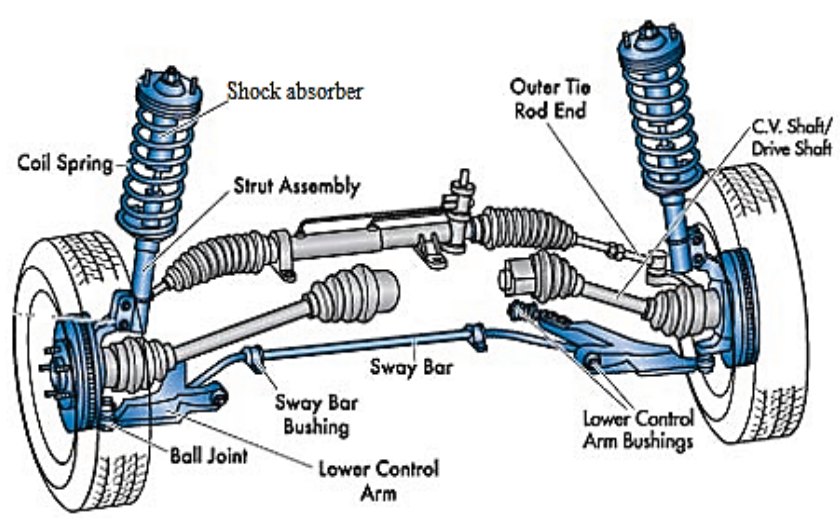

Figure 1 A typical road vehicle front suspension system [6]

Suspension systems are one of the most important vehicle components that provide the connection between the vehicle body and the wheels. The most important function of an ordinary vehicle suspension system is to provide road holding, drive control and travel comfort by damping the vertical and momentary movements (vibrations) transmitted from the wheels due to obstacles, structural obstacles, etc. during the wheel-road contact. A suspension system generally consists of a shock absorber and a spring element.
The most common type of a shock absorber used today is the hydraulic absorber. In the hydraulic shock absorber, piston transfers the relative motion, which occurs in one direction (vibration), to viscous oil. In this way, the vibration energy is dissipated by the shock absorber by being converted to heat [10]. The suspension system also maintains the friction between the wheels and the road, ensures constant contact and prevents the vehicle from slipping off the road $[11,12]$. The front suspension system, known as independent suspension (MacPherson), and widely used in road vehicles is shown in Fig. 1 [6].

In recent years, the consciousness of contribution to the fuel economy and environmental sensitivity have accelerated the studies on the development of energy recovery systems for the automotive sector. In particular, the potential of vibration energy dissipated as heat from conventional vehicle suspension systems has attracted the attention of researchers. In the direction of the studies which have continued for 25 years on waste energy recovery from suspension systems, it has been reported that the energy potential has values ranging from 46 to $7500 \mathrm{~W}$ with various parameters [13]. Theoretically, the amount of vibration energy that could be recovered increases with vibration amplitude values, and the highest energy value could be obtained at the resonance frequency [14]. However, the vibration that can safely be damped by conventional suspension in vehicles is in the frequency range of $0.5-10 \mathrm{~Hz}[15]$.

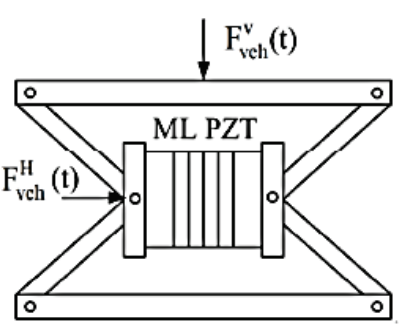

(a)

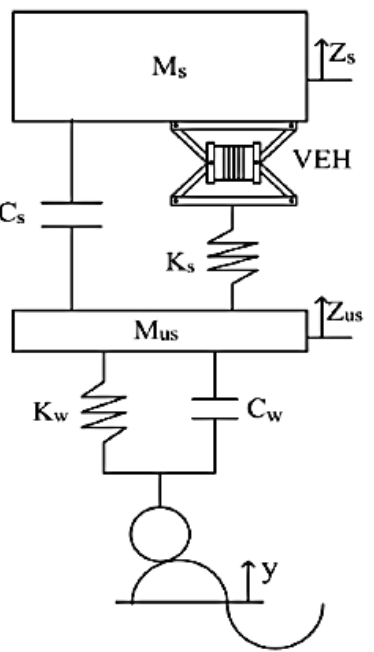

Figure 2 (a) A multilayer piezoelectric vibration energy harvesting mechanism (ML PZT VEH) [9],

(b) A multi-mode vibration-based energy harvester [17]

An electromagnetic shock absorber was designed and optimized by Zuo et al. [14]. The results that were obtained from the finite element analysis with the model and the experiments performed with the 1:2 scale prototype have been seen as consistent with each other. Hadas et al. [16] designed a mechatronic system that is sensitive to energy recovery from vibrations in aviation applications. The power output of $35 \mathrm{~mW}$ was obtained. Hendrowati et al. [9] performed a simulation analysis by generating a 1-degree-offreedom mathematical model of the multilayer piezoelectric vibration energy recovery system (ML PZT VEH) that they developed. The maximum $6.23 \mathrm{~V}$ voltage and $1.6 \mathrm{~mW}$ power output values were obtained from the 2-degree-of-freedom quarter car model (suspension test setup) to which the ML PZT VEH mechanism was adapted (Fig. 2(a)). Furthermore, any effect that may cause a change in the performance of vehicle suspension systems was not observed with this design. Sultoni et al. [10] designed two types of electromagnetic energy harvesting systems as linear and rotational. For these two types of systems, a comparison of the amount of energy recovered and driving comfort levels was made through a simulation analysis on a quarter car 
model. As a result, a power output of $2.5 \times 10^{-4} \mathrm{~W}$ was obtained for the rotary type when a power output of $90 \mathrm{~W}$ output was gained for the linear type. Moreover, it has been concluded that the linear type is more preferable due to the fact that it provides comfort and driving safety and a faster vibration damping than the rotary type. However, the linear type system has a more complex structure than the rotary type system. Hashimoto et al. [17] designed a specific model by using actual driving parameters to achieve a re-usable power output from the source of vibration from typical multi-mode vibrations which occur in vehicles (Fig. 2(b)). This design was made of lead zirconate titanate (PZT) plate springs connecting between three masses. Simulation analyses and experimental results for this design were founded to be consistent with each other.

Zhu et al. [18] reported that the mechanical energy of damped vibrations during driving has the potential to meet the energy needs of wireless sensors in vehicles. As the results of tests performed on roads with three different surface roughness grades classified according to the International Roughness Index (IRI), the power output values of $1.1 \mu \mathrm{W}$ (highest $6 \mu \mathrm{W}$ ) for the class A road, $5.2 \mu \mathrm{W}$ (highest $35 \mu \mathrm{W}$ ) for the class $\mathrm{C}$ road and $13.1 \mu \mathrm{W}$ (maximum $130 \mu \mathrm{W}$ ) for the class E road were recorded. According to the power output values gained from experiments, on the road with the class E surface quality, there was the potential to meet the energy need of the wireless sensors through the designed piezoelectric energy recovery device. Moreover, they reported that the position where the energy recovery system had been installed in the vehicle was important. The highest amount of energy recovery was obtained at the rear suspension of the vehicle and also near the trunk.

Zuo et al. [13] recorded the amount of vibration energy, which could be recovered between 100-400 W, through the analyses of the mathematical model with the quarter car model and the actual driving experiments. Lafarge et al. [19] reported that the vibration energy of $0.5 \mathrm{~mW}$ was recovered at a speed of $30 \mathrm{~km} / \mathrm{h}$ with the piezoelectric (PZT5H) energy harvesting system with the quarter car model. Shah et al. [20] gained $100 \mathrm{~V}$ voltage value at a speed of $10 \mathrm{~km} / \mathrm{h}$ and $180 \mathrm{~V}$ at a speed of $20 \mathrm{~km} / \mathrm{h}$ on a relatively smooth road; $160 \mathrm{~V}$ at a speed of $10 \mathrm{~km} / \mathrm{h}$ and $320 \mathrm{~V}$ at a speed of $20 \mathrm{~km} / \mathrm{h}$ passing over a bump with an electromagnetic energy harvester they designed. In this design, shock waves are damped by the electromagnetic field generated by natural magnets instead of damping with hydraulic oil (Fig. 3(a)). Zhang et al. [21] introduced a novel electro-hydraulic energy harvesting damper for large weighted vehicles and poor road conditions, such as off-road driving (Fig. 3(b)). First, the dynamic model was mathematically expressed. Then, the prototype of the damper was manufactured, and experiments were conducted to investigate the effectiveness of the damping characteristics and energy harvesting capability. The maximum output power of $200 \mathrm{~W}$ and the average of $110.6 \mathrm{~W}$ were obtained with the maximum excitation speed of $0.52 \mathrm{~m} / \mathrm{s}$ and external load of $10 \Omega$. Through this design, unidirectional generator rotation realized, and thereby the energy harvesting efficiency was improved. Furthermore, the undesired temperature rise of damper oil was avoided and it even remained nearly constant through this design.
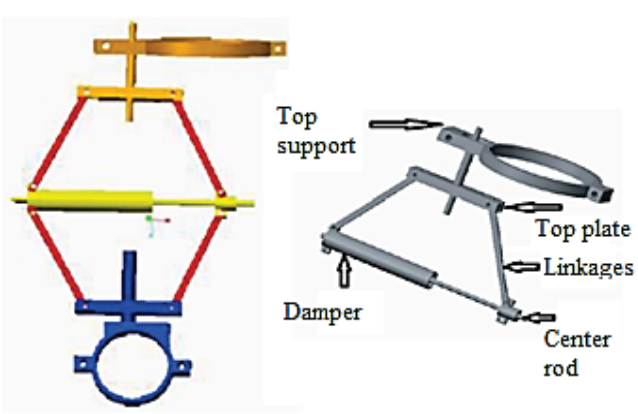

(a)

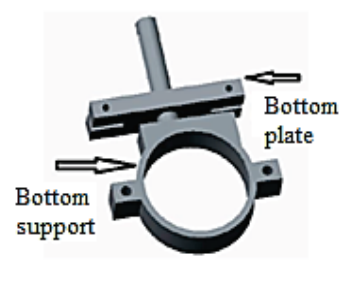

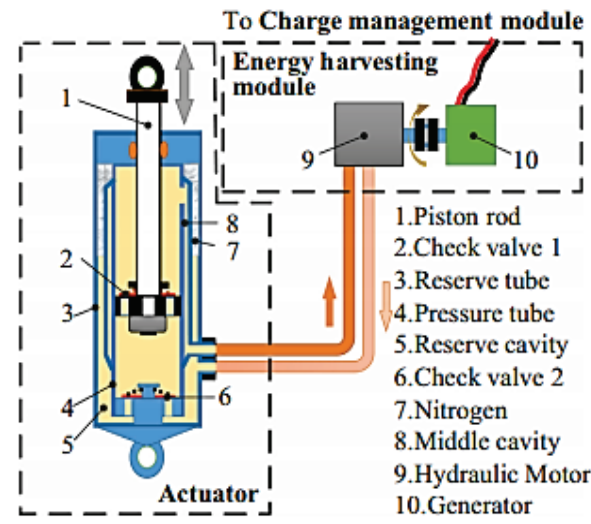

(b)

Figure 3 Designs of (a) an electro-magnetic shock absorber energy harvesting system [20] and (b) an electro-hydraulic shock absorber energy harvesting system [21]

Adly et al. [22] presented an analytical approach for suspension systems such as electromagnetic energy harvesters whose components are nonlinear due to being flexibly tunable. In this approach, the finite-difference numerical analysis method was employed. The results of the analytical approach coincided with the simulations performed. Xie et al. [23] evaluated the effectiveness of the dual-mass piezoelectric energy harvesting system that they mathematically modelled according to structural design parameters and driving conditions and the accompanying numerical simulations. They gained values of a power output up to $738 \mathrm{~W}$. Demetgul et al. [24] designed a hybrid vibration energy harvesting suspension which is similar both to hydraulic and electromagnetic systems in terms of the operating principle. In the experimental studies; the power outputs of $0.25 \mathrm{~W}, 0.4 \mathrm{~W}$ and $0.66 \mathrm{~W}$ were obtained for the damping rates of $0.004 \mathrm{~m} / \mathrm{s}, 0.0045 \mathrm{~m} / \mathrm{s}$ and $0.005 \mathrm{~m} / \mathrm{s}$, respectively. As a result of simulations carried out for other hybrid energy harvesting suspension systems designed by Xie et al. [25], it was found that vibration energy was directly related to road roughness and the speed of the vehicle. With the simulations performed for this design, at a speed of 120 $\mathrm{km} / \mathrm{h}$, the power output of $40 \mathrm{~W}$ was harvested from the suspension system on a road with Class B surface roughness 
and $140 \mathrm{~W}$ on the road with Class $\mathrm{C}$ surface roughness. Satpute et al. [26] designed the passive hybrid system (hydraulic-electromagnetic shock absorber (HESA)). They aimed to increase the amount of energy that could be harvested from the electromagnetic part by increasing the moving speed of the fluid (viscous oil) in the mechanical (damper) part. The results of the experimental and theoretical studies are compatible with each other. Through the experiments performed with the prototype which was at the actual measurements, for different vibration amplitudes, the power output values varying from 18 to $227 \mathrm{~W}$ were gained. Mucka [27] assessed the actual energy potential that could be recovered from the suspension systems under real driving conditions. Through an ordinary car (with nine degrees of freedom), he examined the relation between the amount of energy dissipated from suspension systems and the type of road surface, the speed of the vehicle, road roughness values and the contact type parameters between the wheel and road. Zhang et al. [28] presented an original energy recovery suspension system with a hydraulic pumping mechanism consisting of an energy storage unit and a hydraulic actuator. They defined the mathematical model of the system and studied the parameters such as different vibration frequencies and electrical loads to improve the characteristics of the damper and the energy recovery efficiency. Because of parameter optimization, the best power output value from the system was obtained as $33.4 \mathrm{~W}$ for each suspension. Kim et al. [29] designed a regenerative suspension combined with a linear generator. The armature part was composed of a 16pole and 16-slot Halbach array of radial and axial permanent magnets. The linear generator was capable of gathering more than $100 \mathrm{~W}$ of average power and $250 \mathrm{~W}$ of maximum power for full-sized civilian or military vehicles. As a result of the simulation analyses, the initial model also provided the maximum power of $370.38 \mathrm{~W}$ and the average power of $133.26 \mathrm{~W}$. They later optimized their model in terms of four parameters (tooth thickness, tooth width, radial permanent magnet thickness, and axial permanent magnet width) and provided a $57.8 \%$ higher efficiency than that of the initial model.

\subsection{Energy Harvesting by Braking (Regenerative Braking)}

One of the inevitable energy losses in the vehicles is the one that that occurs with braking. When the brake is applied during the motion, the brake pads impose pressure on the wheel disc to reduce the speed or stop the vehicle. While the vehicle slows down, the kinetic energy is dissipated as heat due to friction. The amount of this transformed energy due to braking depends on how frequently braking is applied, how hard it is done and on the duration of braking.

As opposed to when driving on highways, braking in urban traffic is more frequent. Braking is often applied because of the constant stop-and-go movements in heavy traffic and low speed limits within the city. Depending on the frequency of the use of brakes in the urban traffic, up to 62.5 $\%$ of the vehicle's energy gets lost. However, in the case of completely preventing energy losses of braking and also recovering losses as useful energy, it is predicted that fuel consumption would decrease by $33 \%$. The amount of energy recovered by regenerative braking generally depends on the sort of the storage unit, the efficiency of the powertrain, the driving situation, and the inertia of the vehicle [30].

Basically, braking which provides energy recovery is a process of catching and storing the kinetic energy that normally would be dissipated as heat when the vehicle slows down. The regenerative system transforms this energy into its useful form and keeps it ready for immediate or later use. When regenerative braking is applied, the kinetic energy of the vehicle is transferred by the powertrain to an energy storage unit [31]. Regenerative braking systems vary according to their type of the energy storage unit and the energy conversion method. From past to present, the mostknown braking systems, which provide energy regeneration, have utilized springs, flywheels, electrochemical batteries and hydraulic accumulators as storage units [30].

Studies on regenerative braking started at the end of the 1800 s. The first applications were installations of spring-type regenerative braking systems on the front wheels of bikes and horse-drawn cabs. Systems in which springs are employed as energy storage units are generally run directly by human power, for example bicycles, wheelchairs, etc. The characteristics of a torsion spring used as an energy storage element are determined by the weight and speed capacity of the vehicle [32]. In the 1930s, the regenerative braking technology took part in the Baku-Tbilisi-Batumi railway line [33]. In the 1950s, the Swiss Oerlikon company developed a gyrobus, which uses flywheels as an energy storage unit [34]. In the systems that utilize flywheels as energy storage units, the kinetic energy of the slowing vehicle is transformed into rotational motion energy and is stored by the flywheel. The flywheel is connected to the propeller shaft via a gearbox. An electric generator is employed so that the energy stored in the flywheel can be used in the vehicle's movement. When the vehicle needs propulsion or acceleration, the energy stored in the flywheel is transferred to the drive shaft as torque. The energy stored in the flywheel system is directly related to the weight of the flywheel and the number of revolutions of the flywheel [30, 35]. Unlike the systems using the battery as an energy storage unit, the energy can be regenerated and stored in the flywheel even for short distances and short braking durations [36]. In the systems in which hydraulic accumulators are used as energy storage units, the energy recovered by braking is stored within a pressurized working fluid in a spherical or cylindrical vessel. The working fluid is usually nitrogen gas. When braking is applied, the engine driven by the wheels behaves as a hydraulic pump and compresses the working fluid in the accumulator. Hydraulic accumulator systems are lighter, smaller and cheaper than other systems [30].

Regenerative braking systems have become common with the development of the hybrid/electric vehicle technology. In 1967, the American Motor Vehicle Company (AMC) implemented regenerative braking system to the electric vehicle prototype, AMC Amitron. The first commercial use of the regenerative braking system is the Toyota Prius series [33]. The regenerative braking systems that are integrated into hybrid and electric vehicles utilize 
electrochemical batteries as energy storage units. When the brake is applied, the electric motor acts as a generator that converts kinetic energy into electric energy and transmits it to the battery. When the vehicle needs propulsion or acceleration, the electric motor works as an engine of the vehicle, i.e. it converts the electric energy in the battery to mechanical energy and transfers it to the wheels. The general operation of regenerative braking systems is schematically shown in Fig. 4 [30, 31].
Regenerative Breaking System (Drive Mode)

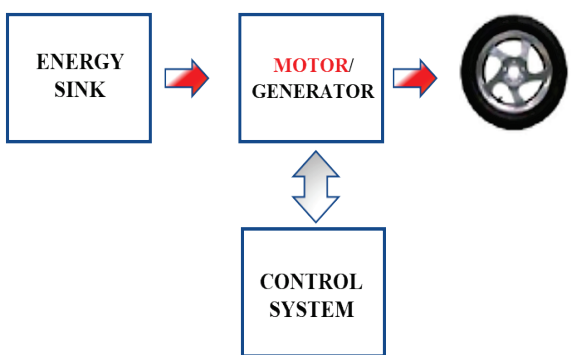

Regenerative Breaking System (Braking Mode)

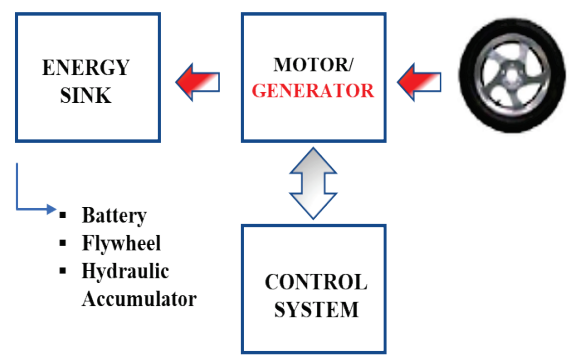

Figure 4 Schematic demonstration of the operation of regenerative braking systems in the case of (a) vehicle is in motion and (b) the braking condition [35]

Since batteries are the only power sources of electric vehicles, the efficiency of a battery directly affects the electrical vehicle's performance. Unfortunately, in real driving conditions, electrochemical batteries limit the performance of electrical vehicles due to fast discharging during acceleration or fast recharging as the braking is applied. Moreover, a battery can be fully charged within 1-3 hours. [37]. It has been experienced from real driving conditions of electric vehicles that at low speeds and short distances, it is not possible to use active recovery braking and conventional braking must also be used for a safe full stop. Furthermore, if the battery is fully charged, regenerative braking will not respond. Adding extra batteries means that there is a requirement of extra space, an increase of total weight and extra cost. The life cycle of batteries is another issue [30]. Therefore, recent studies have advocated for optimizing and managing the existing regenerative braking systems.

Gao et al. [38] proposed a regenerative braking system which would utilize a permanent magnet synchronous motor instead of the systems which use batteries as a propulsion unit. This system has a higher efficiency and a higher torque density. The simulation results of the model that were expressed mathematically have verified the system as suitable for various light electric vehicles. Considering the battery charging capacity, vehicle speed, maximum braking power of the moto, etc., Yanan [39] put forward a control strategy for the regenerative braking system. According to the study, the recovery system's efficiency reaches up to $60 \%$. It was confirmed by some studies $[37,40]$ that adding an ultra-capacitor to increase the performance of regenerative braking in electric/hybrid vehicles allows the storage of 20 times more energy than that of conventional batteries. A bidirectional DC-DC converter (a hybrid energy storage system - HESS) is used to control the current into the classical system of these vehicles. Thus, the limitation of the capacity of electrical energy storage is decreased and the life of the batteries is increased. Moreover, supercapacitors make it possible to regenerate energy from braking at any speed and for any distance. Naseri et al. [41] presented a novel design by excluding the DC-DC converter unit from HESS, for improving the regenerative breaking efficiency and reducing the cost. They achieved an increase of $20 \%$ in the efficiency compared to regenerative braking with a battery energy storage system (ESS) only. The electric vehicle's drive range was increased for about $43 \mathrm{~km}$ by using HESS.

\section{DISCUSSION}

The basic function of the suspension systems in vehicles is to dampen vibrations caused by the road and to maintain the friction between the vehicle and the road; thus, ensuring driving comfort and safety. The road-induced vibrations that occur during driving are damped by conventional hydraulic suspension systems and the mechanical energy of the vibrations is dissipated as heat. However, studies have been conducted on energy harvesting systems for the automotive sector in order to provide fuel efficiency and reduce environmental pollution in vehicles. For nearly 25 years, various energy harvesting suspension systems have been designed with the purpose of recovering the mechanical energy of vibrations instead of being dissipated as heat, transforming them into electrical energy and meeting the energy needs of such parts as various wireless sensors in vehicles. The characteristics of some studies carried out in this direction are given in Tab. 2. Commonly designed systems are: electromagnetic systems, piezoelectric systems, electrohydraulic systems and hybrid systems according to their working principles. It is claimed that mechanical (hydraulic/pneumatic) energy harvesting systems have some deficiencies compared to electromagnetic and piezoelectric energy harvesting systems. Some of them are the following:

- Parts such as pipes / hoses that provide transmission of the damping viscous fluid in the system increase the overall weight and volume of the system. 
- Leaks from the transmission parts can cause the system to become completely ineffective.

- Response bandwidth of the shock absorber fluid is narrow.

- The efficiency of mechanical energy harvesting systems is relatively lower.

For these reasons, mechanical energy harvesting suspension systems are not common [12]. Piezoelectric, electrostatic and electromagnetic energy harvesting systems can convert and store the harvested energy into electricity with higher efficiency because there is no necessity to transform the energy from one type (mechanical) to another (electrical) that causes transforming losses. Moreover, the volume to be occupied by these systems is relatively small [23].

A remarkable conclusion was deduced, that the amount of vibration energy obtained from the energy recovery damping systems is directly related to the speed of the vehicle, the surface quality of the road and the rigidity of the tires; however, other parameters such as suspension stiffness, the damping degree of suspension, sprung mass and unsprung mass only affect ride comfort and safety [13].

Table 2 Studies on energy harvesting suspension systems and their characteristics

\begin{tabular}{|c|c|c|c|c|c|}
\hline Reference & Energy Harvesting System & Method & Road Roughness & Vehicle Velocity & Power Output \\
\hline \multirow{2}{*}{ Zuo et al. [13] } & \multirow{2}{*}{ ( } & \multirow{2}{*}{$\begin{array}{c}\text { Analytical, } \\
\text { Experimental }\end{array}$} & \multirow{2}{*}{$\begin{array}{c}\text { B,C } \\
\text { Urban road }\end{array}$} & $97 \mathrm{~km} / \mathrm{h}$ & $100-400 \mathrm{~W}$ \\
\hline & & & & $40 \mathrm{~km} / \mathrm{h}$ & $58 \mathrm{~W}$ \\
\hline Zuo et al. [14] & $\begin{array}{c}\text { Linear electromagnetic } \\
\text { system }\end{array}$ & Analytical, Experimental & Highway & - & $16-64 \mathrm{~W}$ \\
\hline Hadas et al. [16] & Mechatronic system & Experimental & (Laboratory) & - & $7,7-35 \mathrm{~mW}$ \\
\hline Hendrowati et al. [9] & $\begin{array}{c}\text { Multilayered piezoelectric } \\
\text { system }\end{array}$ & Analytical & - & $43.2 \mathrm{~km} / \mathrm{h}$ & $1,6 \mathrm{~mW}$ \\
\hline \multirow{2}{*}{ Sultoni et al. [10] } & $\begin{array}{c}\text { Rotational type } \\
\text { electromagnetic system }\end{array}$ & \multirow{2}{*}{ Analytical } & \multirow{2}{*}{ - } & \multirow{2}{*}{ - } & $2.5 \times 10^{-4} \mathrm{~W}$ \\
\hline & $\begin{array}{c}\text { Linear type electromagnetic } \\
\text { system }\end{array}$ & & & & $90 \mathrm{~W}$ \\
\hline \multirow{3}{*}{ Zhu et al. [18], } & \multirow{3}{*}{ Piezoelectric system } & \multirow{3}{*}{ Experimental } & $\mathrm{A}$ & \multirow{3}{*}{$\begin{array}{l}30 \mathrm{~km} / \mathrm{h} \\
60 \mathrm{~km} / \mathrm{h}\end{array}$} & $1.1 \mu \mathrm{W}$ \\
\hline & & & $\mathrm{C}$ & & $5.2 \mu \mathrm{W}$ \\
\hline & & & $\mathrm{E}$ & & $13.1 \mu \mathrm{W}$ \\
\hline Lafarge et al. [19] & Piezoelectric (PZT5H) system & Experimental & (Laboratory) & $30 \mathrm{~km} / \mathrm{h}$ & $0.5 \mathrm{~mW}$ \\
\hline \multirow{4}{*}{ Shah et al. [20] } & \multirow{4}{*}{ Electromagnetic system } & \multirow{4}{*}{ Analytical } & \multirow{2}{*}{ Smooth road } & $10 \mathrm{~km} / \mathrm{h}$ & $100 \mathrm{mV}$ \\
\hline & & & & $20 \mathrm{~km} / \mathrm{h}$ & $180 \mathrm{mV}$ \\
\hline & & & \multirow{2}{*}{ Speed bump } & $10 \mathrm{~km} / \mathrm{h}$ & $160 \mathrm{mV}$ \\
\hline & & & & $20 \mathrm{~km} / \mathrm{h}$ & $320 \mathrm{mV}$ \\
\hline Zhang et. al [21] & Electro-hydraulic system & $\begin{array}{l}\text { Analytical, } \\
\text { Experimental }\end{array}$ & off-road & $\begin{array}{c}\text { excitation speed of } \\
0.52 \mathrm{~m} / \mathrm{s} \\
\end{array}$ & $\begin{array}{l}200 \mathrm{~W} \text { (max.) } \\
110.6 \mathrm{~W} \text { (avg.) }\end{array}$ \\
\hline Adly et al. [22] & Electromecanical system & Analytical & - & - & $4 \mathrm{~W}$ \\
\hline Xie et al. [23] & Piezoelectric system & Analytical & - & - & $738 \mathrm{~W}$ \\
\hline Demetgul et al. [24] & Hybrid system & Experimental & (Laboratory) & - & $0.25-0.66 \mathrm{~W}$ \\
\hline Xie et al. [25] & Hybrid system & $\begin{array}{c}\text { Analytical, } \\
\text { Experimental }\end{array}$ & $\begin{array}{l}\mathrm{B} \\
\mathrm{C}\end{array}$ & $120 \mathrm{~km} / \mathrm{h}$ & $\begin{array}{c}40 \mathrm{~W} \\
140 \mathrm{~W}\end{array}$ \\
\hline Satpute et al.[26] & Hybrid system & $\begin{array}{l}\text { Analytical, } \\
\text { Experimental }\end{array}$ & - & - & $18-227 \mathrm{~W}$ \\
\hline Zhang et al. [28] & Hydraulic system & Analytical & uneven & - & $33.4 \mathrm{~W} /$ per suspension \\
\hline \multirow{2}{*}{ Kim et al. [29] } & \multirow{2}{*}{ Electromagnetic system } & Analytical (initial) & \multirow{2}{*}{$\begin{array}{l}\text { Road surface } \\
\text { frequency of } \\
10 \mathrm{~Hz}\end{array}$} & \multirow{2}{*}{ - } & $\begin{array}{l}370.38 \mathrm{~W} \text { (max.) } \\
133.26 \mathrm{~W} \text { (avg.) } \\
\end{array}$ \\
\hline & & Analytical (optimized) & & & $\begin{array}{c}586.43 \mathrm{~W} \text { (max.) } \\
214.98 \text { (avg.) }\end{array}$ \\
\hline
\end{tabular}

Another energy recovery method is the use of regenerative braking systems. Regenerative braking is a process that catches and converts the slowing down vehicle's kinetic energy which is normally dissipated as heat in the case of braking and the process stores it as useful energy (electric energy). The amount of energy recovered by regenerative braking generally depends on the sort of the storage unit, the efficiency of the powertrain, driving conditions, and the inertia of the vehicle. Regenerative braking systems vary according to their type of the energy storage unit and energy conversion method. Energy storage units that have been utilized are springs, flywheels, electrochemical batteries and hydraulic accumulators. Among all of them, the most common and updated regenerative braking system is the one that utilizes electrochemical batteries and is currently used in hybrid and electric vehicles.

Since they are the only power source of electric vehicles, the total efficiency of regenerative braking systems and the performance of the vehicle depend on batteries. However, batteries have issues that limit the performance of the whole system such as an unsatisfying charging capacity and charging ratio, lifetime, energy transfer ratio, etc. In real driving conditions, electrochemical batteries limit the performance of electrical vehicles due to their fast discharging during acceleration or fast recharging as braking is applied. For low speeds and short distances, it is not 
possible to use active recovery braking; therefore, conventional braking must also be used for a safe full stop.

Recent studies have dealt with eliminating the disadvantages of regenerative braking. A common method is constituting a system that employs an energy storage unit called "supercapacitors", an auxiliary to classic batteries. Supercapacitors provide many advantages such as charging in a short time, wide operating temperature range, extended run time and safety, having high power density, more efficient regenerative braking and improving vehicle acceleration [41]. However, supercapacitors have the highest cost per kWh compared to batteries or flywheel. Therefore, a specific control strategy is needed in order to use supercapacitors efficiently. Furthermore, supercapacitors contain insulator fluids which are flammable and toxic and hazardous failure modes occur if supercapacitors are subjected to overvoltage [42].
The flywheel, as another energy storage unit, can take part in regenerative braking systems. During the energy harvesting process, the losses can be avoided due to the fact that the harvested mechanical energy is transmitted without any transformation to another energy form. Thus, a flywheel has a better efficiency compared to a battery. Because they have higher power density, flywheels can deliver energy at a high rate. The operation temperature range of flywheels is wider and the operation life is longer than that of batteries. It was also concluded that flywheels are not as detrimental as batteries. Flywheels have limitations along with their advantages. Flywheels have a higher cost per $\mathrm{kWh}$ compared to batteries. Because they are a mechanical device, safety concerns must be resolved for any moving parts, bearing failures, etc. [42]

General properties of regenerative braking systems and expectations are summarized in Tab. 3 .

Table 3 Comparison of the general characteristics of the regenerative braking system

\begin{tabular}{|l|l|l|}
\hline \multicolumn{1}{|c|}{$\begin{array}{c}\text { Features of an ideal regenerative braking system } \\
{[30]}\end{array}$} & \multicolumn{1}{c|}{$\begin{array}{c}\text { Advantages of regenerative braking systems } \\
{[43]}\end{array}$} & \multicolumn{1}{|c|}{$\begin{array}{c}\text { Deficiencies of regenerative braking systems } \\
\text { [43] }\end{array}$} \\
\hline - High efficiency of energy conversion & - Decrease in $\mathrm{CO}_{2}$ emissions & $\begin{array}{l}\text { - Increase in vehicle weight, increase in required } \\
\text { volume }\end{array}$ \\
\hline $\begin{array}{l}\text { - High capacity energy storage per vehicle weight } \\
\text { and volume }\end{array}$ & - Contribution to the fuel economy & $\begin{array}{l}\text { - Increase in the number of systems in the vehicle, } \\
\text { resulting in complexity }\end{array}$ \\
\hline $\begin{array}{l}\text { - Braking end kinetic energy can be stored with a } \\
\text { minimum loss and delay }\end{array}$ & - Outstanding performance & - Increase in cost \\
\hline $\begin{array}{l}\text { - Minimal loss and delay of kinetic energy storage } \\
\text { for a wide vehicle speed and wheel torque range }\end{array}$ & - Reduction of motor wears & $\begin{array}{l}\text { - Noise due to the structure and operation of the } \\
\text { system }\end{array}$ \\
\hline $\begin{array}{l}\text { - Easy transfer of energy from the regenerative } \\
\text { system }\end{array}$ & - Reduction of braking system wears & - Unexpected failures in the system \\
\hline - A non-complicated system & - Smaller components & - Dimensional constraints \\
\hline $\begin{array}{l}\text { - High power ratio to allow large quantities of } \\
\text { energy to be transferred in a short time }\end{array}$ & - Extra system maintenance requirement \\
\hline
\end{tabular}

\section{CONCLUSIONS}

In today's world, energy and environment are the most crucial matters. The widespread and increasing consumption of fossil-based fuels as an energy source causes a rapid decrease of these sources and an increase of pollution in the atmosphere. This situation has raised awareness about the importance of contributing to the fuel economy and environmental consciousness. Therefore, some measures had to be taken in many industrial sectors. One of these sectors is the automotive sector, which has a big amount of energy consumption, and also a big potential for energy saving.

In this context, research studies have been made for detecting the energy losses that occur during the driving of vehicles and consequently for the reduction of these losses to the possible lowest level. Regaining of energy losses has also been researched. In this study, the previous studies related to energy regaining (harvesting) methods and systems in vehicles were compiled and discussed. Today, the most common of these methods are the vibration energy harvesting via suspension systems and kinetic energy regeneration via braking systems.

Several designs of energy harvesting suspension systems have been presented and optimized in order to ensure a better performance for different applications for the past 25 years. Through various energy harvesting suspension systems that have been designed, the mechanical energy of road-induced vehicle vibrations has been successfully recovered in varying quantities. Moreover, regenerative braking has existed for over 100 years and has already been available and applied to hybrid and electric vehicles commercially. However, both the energy harvesting suspension systems and regenerative braking technology is still under continuous development.

It can be concluded through studies that both energy harvesting methods have limitations such as total weight increases, extra space requirements, efficiency losses, costs, etc. In this respect, optimizations continue for more light weighted designs with choosing the more suitable material selection and dimensional designs. For regenerative suspensions, instead of mechanical weighted systems (hydraulic and pneumatic systems), the choice of electronic (electromagnetic/piezoelectric) component weighted systems is more favorable in terms of lightness, relatively less occupied volume, and efficiency in converting mechanical energy to electrical energy. Theoretically, the highest vibration energy recovery is provided in the resonance case. Thus, more energy can be harvested by increasing the natural frequency bandwidth of energy recovery suspension systems.

In regenerative braking systems, the type of energy storage units plays a decisive role. There are four energy storage units: electrochemical batteries, springs, flywheels 
and hydraulic accumulators. Today, the most common regenerative braking system is the one that utilizes electrochemical cells. However, batteries also have shortages such as the charging capacity, energy transfer rate and life cycle which limit the electric/hybrid cars' performance. Recent studies have been improved by using supercapacitors because they fill this gap. Flywheels are also a prominent choice for hybrid vehicles due to their high energy transmitting rate.

\section{REFERENCES}

[1] https://www.iea.org/publications/freepublications/publication/ KeyWorld2016.pdf

[2] https://www.epa.gov/ghgemissions/global-greenhouse-gasemissions-data

[3] Deulgaonkar, V. R., Kallurkar, S. P., Mattani, A. G. (2011). Review and Diagnostics of noise and vibrations in automobiles, International Journal of Modern Engineering Research (IJMER), 1(2), 242-246.

[4] Mohamad S. H., Thalas, M. F., Noordin, A., Yahya, M. S., Hassan, M. H. C, Ibrahim, Z., (2015). A potential study of piezoelectric energy harvesting in car vibration, ARPN Journal of Engineering and Applied Sciences, 10(19), 8642-8647,

[5] Harkude, M. N., Malagi, R. R., Automobile noise and vibration-sources, prediction, and control, Indian Journal of Scientific Research, 1-7, 2015.

[6] Lafarge, B., Cagin, S., Curea, O., Perret, A. H., From functional analysis to energy harvesting system design: application to car suspension, International Journal on Interactive Design and Manufacturing (IJIDeM), 10(1), 37-50, 2016. https://doi.org/10.1007/s12008-015-0284-1

[7] Kaźmierski, T. J. \& Beeby, S. (2010). Energy harvesting systems: principles, modeling and applications. Springer Science \& Business Media.

[8] Burdzik, R. \& Doleček, R. (2012). Research of vibration distribution in vehicle constructive. Perner's Contacts, 7(4), 16-25.

[9] Hendrowati, W., Guntur, H. L., \& Sutantra, I. N. (2012). Design, modeling and analysis of implementing a multilayer piezoelectric vibration energy harvesting mechanism in the vehicle suspension, Engineering, 4(11), 728. https://doi.org/10.4236/eng.2012.411094

[10] Sultoni, A. I., Sutantra, I. N., \& Pramono, A. S. (2013). Vibration Energy harvesting on Vehicle Suspension Using Rotary and Linear Electromagnetic Generator. IPTEK The Journal for Technology and Science, 24(1). https://doi.org/10.12962/j20882033.v24i1.136

[11] Abdullah, M. A. \& Jamil, J. F. (2015). Harvesting energy from the vibration of suspension of a passenger vehicle. Recent Advances in Mechanics and Mechanical Engineering, 128133.

[12] Jin-qiu, Z., Zhi-zhao, P., Lei, Z., \& Yu, Z. (2013). A review on energy-regenerative suspension systems for vehicles. In Proceedings of the World Congress on Engineering, 3, 3-5.

[13] Zuo, L. \& Zhang, P. S. (2013). Energy harvesting, ride comfort, and road handling of regenerative vehicle suspensions. Journal of Vibration and Acoustics, 135(1), 011002-1 - 011002-8. https://doi.org/10.1115/1.4007562

[14] Zuo, L., Scully, B., Shestani, J., \& Zhou, Y. (2010). Design and characterization of an electromagnetic energy harvester for vehicle suspensions. Smart Materials and Structures, 19(4), 045003. https://doi.org/10.1088/0964-1726/19/4/045003
[15] Jha, S. K. (1976). Characteristics and sources of noise and vibration and their control in motor cars. Journal of Sound and Vibration, 47(4), 543-558. https://doi.org/10.1016/0022-460X(76)90881-6

[16] Hadas, Z., Vetiska, V., Singule, V., Andrs, O., Kovar, J., \& Vetiska, J. (2012). Energy harvesting from mechanical shocks using a sensitive vibration energy harvester. International Journal of Advanced Robotic Systems, 9(5), 225. https://doi.org/10.5772/53948

[17] Hashimoto, S., Nagai, N., Fujikura, Y., Takahashi, J., Kumagai, S., Kasai, M., Suto, K., \& Okada, H. (2013). A Multi-Mode Vibration-Based Power Generator for Vehicles. In Applied Mechanics and Materials, 251, 124-128. https://doi.org/10.4028/www.scientific.net/AMM.251.124

[18] Zhu, Q., Li, Y., He, Y., \& Guan, M. (2014). Piezoelectric Energy harvesting in Automobiles. Ferroelectrics, 467(1), 3341. https://doi.org/10.1080/00150193.2014.932165

[19] Lafarge, B., Delebarre, C., Grondel, S., Curea, O., \& Hacala, A. (2015). Analysis and Optimization of a Piezoelectric harvester on a Car Damper. Physics Procedia, 70, 970-973. https://doi.org/10.1016/j.phpro.2015.08.202

[20] Shah, K. L. \& Satpute, N. V. (2015). Analysis of a vehicle suspension with electromagnetic harvester. SSRG International Journal of Mechanical Engineering (SSRG-IJME), 2(7), 66-72.

[21] Zhang, Y., Chen, H., Guo, K., Zhang, X., \& Li, S. E. (2017). Electro-hydraulic damper for energy harvesting suspension: Modeling, prototyping and experimental validation. Applied energy, 199, 1-12. https://doi.org/10.1016/j.apenergy.2017.04.085

[22] Adly, A. A. \& Adly, M. A. (2016). Utilizing electromechanical energy harvesting in vehicle suspension vibration damping. In Electronics, Circuits and Systems (ICECS), 672-675. https://doi.org/10.1109//CECS.2016.7841291

[23] Xie, X. D. \& Wang, Q. (2015). Energy harvesting from a vehicle suspension system. Energy, 86, 385-392. https://doi.org/10.1016/j.energy.2015.04.009

[24] Demetgul, M. \& Guney, I. (2017). Design of the hybrid regenerative shock absorber and energy harvesting from linear movement. Journal of Clean Energy Technologies, 5(1), 8184. https://doi.org/10.18178/JOCET.2017.5.1.349

[25] Xie, L., Li, J., \& Cai, M. (2015). Design of a hybrid energy-ing shock absorber. International Forum on Energy, Environment Science and Materials (IFEESM 2015), 427-431.

[26] Satpute, N. V., Satpute, S. N., \& Jugulkar, L. M. (2017). Hybrid electromagnetic shock absorber for energy harvesting in a vehicle suspension. Proceedings of the Institution of Mechanical Engineers, Part C: Journal of Mechanical Engineering Science, 231(8), 1500-1517. https://doi.org/10.1177/0954406216663577

[27] Múčka, P. (2016). Energy-ing potential of automobile suspension. Vehicle System Dynamics, 54(12), 1651-1670. https://doi.org/10.1080/00423114.2016.1227077

[28] Zhang, Y., Zhang, X., Zhan, M., Guo, K., Zhao, F., \& Liu, Z., (2015). Study on a novel hydraulic pumping regenerative suspension for vehicles. Journal of the Franklin Institute, 352(2), 485-499. https://doi.org/10.1016/j.jfranklin.2014.06.005

[29] Kim, J. H., Shin, Y. J., Do Chun, Y., \& Kim, J. H. (2018). Design of 100W Regenerative Vehicle Suspension to Harvest Energy from Road Surfaces. International Journal of Precision Engineering and Manufacturing, 19(7), 1089-1096. https://doi.org/10.1007/s12541-018-0129-5

[30] Clegg, S. J. (1996). A review of regenerative braking systems.

[31] Gupta, P., Kumar, A., Deb, S., \& Shayan. (2014). Regenerative Braking Systems (RBS) (Future of Braking Systems). International Journal of Mechanical and Production Engineering, 2(5), 75-78. 
[32] Kalayarasan, M. (2016). Torsion spring regenerative braking in automobile a conceptual idea. IJAR, 2(9), 171-174.

[33] Clark II, W. W. \& Cooke, G. (2011). Global Energy Innovation: Why America Must Lead. ABC-CLIO.

[34] Hampl, J. (2013). Concept of the Mechanically Powered Gyrobus. Transactions on Transport Sciences, 6(1), 27-38. https://doi.org/10.2478/v10158-012-0029-9

[35] Intwala, A. B. \& Ahmed, A. (2016). Regenerative braking system using flywheel. International Journal of Scientific Research, 5(4), 644-645.

[36] Rahane, C. \& Varpe, V. (2016). Design and fabrication of regenerative braking system. International Advanced Research Journal in Science, Engineering and Technology $2^{\text {nd }}$ International Conference on Advances in Mechanical Engineering (ICAME-2016), 3(1), 20-25.

[37] Gopinathan, S. S., Akshara, I. P., Gibi, M., Jamshad, M., \& Sadique, V. P. (2015). Electrical vehicle with regenerative braking system by using super capacitors. International Journal of Electrical and Electronics Research, 3(2), 188-121.

[38] Gao, Q., Lv, C., Zhao, N., Zang, H., Jiang, H., Zhang, Z., \& Zhang, F. (2018). Regenerative braking system of PM synchronous motor. In AIP Conference Proceedings, 1955(1), p. 040111. https://doi.org/10.1063/1.5033775

[39] Yanan., G. (2016). Research on electric vehicle regenerative braking system and energy recovery. International Journal of Hybrid Information Technology, 9(1), 81-90. https://doi.org/10.14257/ijhit.2016.9.1.08

[40] Malode, S. K. \& Adware, R. (2016). Regenerative Braking System In Electric Vehicles. International Research Journal of Engineering and Technology (IRJET), 3(3), 394-400.

[41] Naseri, F., Farjah, E., \& Ghanbari, T., An efficient regenerative braking system based on battery/supercapacitor for electric, hybrid, and plug-in hybrid electric vehicles with BLDC motor. IEEE Transactions on Vehicular Technology, 66(5), 3724-3738, 2017.

[42] Sharma, P. (2015). Regenerative Braking-Methods to Efficiently Use Regenerated Energy. Journal of Electrical \& Electronics, 4(2), 1.

[43] Pourmovahed, A. (1991). Vehicle propulsion systems with hydraulic energy storage: a literature survey. International Journal of Vehicle Design, 12(4), 378-403.

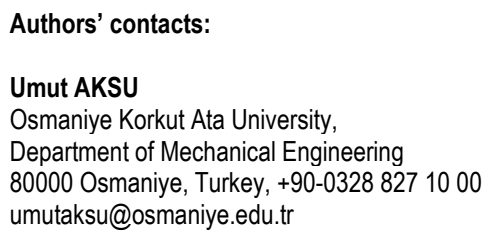

Recep HALICIOGLU, PhD, Corresponding author recephalicioglu@gmail.com 